\title{
Vocabulary Retention and Concordance-based Learning in L3 Acquisition
}

\author{
Irina Rets ${ }^{\text {* }}$ \\ ${ }^{a}$ Sakarya University, Education Faculty, Hendek, 54300, Turkey
}

Received 24 July 2017 | Received in revised form 10 September 2017 | Accepted 11 September 2017

\begin{abstract}
Vocabulary knowledge is considered to be key to language comprehension and speech production. Although there is considerable research literature on vocabulary learning, there is no consensus on which vocabulary teaching / learning strategy is the most successful. The article describes the findings of an experimental research study aimed at analysing the effect of concordance-based learning on L3 vocabulary acquisition and retention. L3 is understood in the present research as a chronologically third language acquired by a speaker (Mayo, 2012). The study features 48 participants learning German as a second foreign language subsequently to English who were divided randomly into experimental and control groups. While the experimental group learnt words with the help of online concordance, the control group worked with conventional vocabulary worksheets. A pre-test, a post test, and a delayed vocabulary recall test were conducted with both groups. The study showed that the experimental group outperformed the control group in both post- and delayed tests. The aspect of vocabulary knowledge that was acquired and retained more successfully with concordance-based activities was making up sentences and building collocations with the given key words. The study also demonstrated the usability of concordance-based learning with A1 language level students within the framework of L3 acquisition.
\end{abstract}

(C) 2017 EJAL \& the Authors. Published by Eurasian Journal of Applied Linguistics (EJAL). This is an open-access article distributed under the terms and conditions of the Creative Commons Attribution license (CC BY-NC-ND) (http://creativecommons.org/licenses/by-nc-nd/4.0/).

Keywords: Concordance; corpus linguistics; vocabulary learning; L3 acquisition; data-driven learning

\section{Introduction}

Traditionally teaching vocabulary takes the central role in language lessons as it is believed that without sufficient vocabulary knowledge, little can be expressed and understood in any language. In fact, this idea is justified by my inquiry in online feedback service 'AnswerGarden' that I launched before conducting research. In this inquiry I asked Internet users to define language and provide answers up to twenty characters in length. Most generated replies appeared to focus on the notion of vocabulary: 'words', 'communication', 'sense', 'name', 'concept', 'expression' etc., which means that vocabulary command is recognized by the respondents as the notion that

\footnotetext{
* Irina Rets.

E-mail address: irinarets@sakarya.edu.tr

http://dx.doi.org/.
} 
takes the primary role when it comes to language. The fact that we need vocabulary to define language phenomenon itself is another evidence of its significance in daily communication and language teaching. As Schmitt and Schmitt (2014) observed, 'learners carry around dictionaries and not grammar books' (p. 4).

There can be different focal points on analysing vocabulary in language teaching research: the size and type of vocabulary that should be taught to students, methods and scales of assessing vocabulary knowledge, and not least of all the strategies of vocabulary teaching. In the latter case the choice of a particular teaching strategy may depend on the understanding of what it means to 'know' a word. When I asked my students who I carried out my research study with, what they understand by 'knowing' the word, most of them considered a word learned if they know its primary meaning. A closer look on vocabulary knowledge shows that the understanding of the word is multi-level in nature. By knowing the word one may imply the knowledge of its semantic meaning(s), written and oral form, its grammatical function and potential position in a sentence, collocations which it forms, the register(s) in which it is used, the frequency of its usage in a language, the possible derivations it may have or semantic relationships it may build with other words (i.e. synonyms, antonyms, hyponyms).

Besides the depth or quality of vocabulary knowledge mentioned above, there have been initiatives to analyse vocabulary knowledge as a receptive-productive continuum: "we should think of vocabulary knowledge as a continuum between the ability to make sense of a word and the ability to activate the word automatically for productive purposes" (Faerch, Haastrup, \& Phillipson, 1984, p. 54). Both parts of the continuum can be extended even further: the initial part to no awareness about the word, when we don't know the word exists and the final part - to the integration of the word to the general linguistic competence of the learner.

Although there is considerable research literature on vocabulary learning, the best way to achieve profound vocabulary knowledge is still unclear as it depends on a diverse range of factors such as the context of learning, the aim of the language course and type of the syllabus, personality of the learner, his/her preferred learning style, motivation etc.

In this study, I reviewed the strategies of vocabulary teaching presented in research literature and focused on a particular one - concordance-based learning, described the analysed usability of this strategy in vocabulary teaching and retention within the framework of L3 acquisition.

\section{Literature review}

\subsection{Vocabulary teaching strategies}

Literature review on L2 vocabulary teaching strategies shows that this issue has a highly multi-dimensional character which manifests itself already in different views on its taxonomy. Some studies propose to classify vocabulary teaching strategies by 
function and distinguish metacognitive strategies that involve planning and evaluating of learning done by the students, cognitive - involving reasoning analysis and functional practice and social - encouraging learning through cooperation with other people (Schmitt \& Schmitt, 2014). Language teaching research has developed respective techniques for each of the strategies. Thus, for example, contextual guessing, creating a semantic map of a word or note-taking are methods of cognitive strategies' replication. There have also been suggestions to classify these strategies by language use or way of engaging with language material. Here we have such categories as retrieval strategies or methods of memory searching and rehearsal strategies that help learner store new lexical information into memory ( $\mathrm{Gu}, 2002)$. Another classification differentiates between situations when students are consciously aware of a certain vocabulary learning strategy employed in class and when they have little awareness about the strategies used by the teacher. The latter taxonomy is closely related to the concept of explicit vs. implicit instruction. Explicit vocabulary teaching is defined as instruction aimed directly at helping the learners commit new lexical information to memory. In contrast, implicit vocabulary teaching operates with incidental vocabulary learning, a side product of any language activity not specifically aimed at vocabulary acquisition (Hulstijn, 2001).

In this research, I expanded the existing taxonomy to include the mode of vocabulary teaching: computer-assisted/online vs. traditional offline vocabulary instruction. Literature review showed that although there has been a lot of attention towards vocabulary studies through the means of computer mediation, such mode has not been included in the classifications of vocabulary teaching strategies.

\subsubsection{Corpus linguistics and data-driven learning}

A corpus is traditionally defined as 'a systematic collection of naturally occurring texts (of both written and spoken language)' (O'Keeffe, McCarthy, \& Carter, 2007). Corpus technologies have been employed in language teaching since 1990s as part of data-driven learning approach (DDL). The latter term, coined by T. Johns (1991), within the framework of language teaching describes the process of how language learners become language detectives while exploring language data autonomously with the help of the corpus. It is based on the ideas of learner-centred language teaching, constructivism theory which views learning as an active process, discovery learning, communicative approach to language learning and, partly, lexical grammar theory positing that lexical meaning cannot be isolated from grammatical meaning as they always co-occur together.

The key tool that corpus linguistics and DDL operate with is concordance, which O'Keeffe et al. (2007) describe as a way 'to find every occurrence of a particular word or phrase' (p. 8). With rapid advances of technology, the times of manual concordance are long gone and students can obtain hands-on experience on language from real life communication context with only one click.

Since DDL represents an innovative mode of language teaching there are several issues that differentiate it from traditional teaching. These characteristics can be 
considered at the same time as the advantages or contribution of this approach to the field of teaching.

First, DDL in itself embodies learner autonomy or learner independence as learner becomes the researcher and the control of knowledge acquisition shifts from the teacher to learner, making the classroom as a result more student-centred. Learners are not passive recipients of information, but take on active roles to work through extensive language data to discover rules and patterns embedded in them, they selfregulate their own learning (Guan, 2013). Student-centred environment involves learner as a whole person, and so is potentially motivating.

Secondly, DDL exposes students to highly authentic language input since it is collected from real communicative situations. Outside of DDL framework, authentic materials can be defined as written or spoken texts with the unaltered language data, produced for non-teaching purposes by and for native speakers to convey a message (Beresova, 2015). Authentic materials are opposed to non-authentic artificially simplified texts that are designed to illustrate a certain grammatical topic or vocabulary item. The key arguments that the proponents of authentic texts put forward are that such materials expose students to 'real' target language, provide cultural information about it, relate more closely to learners' needs and support a more creative approach to teaching (Ibid.). Authenticity of corpus data has a potential to improve students' language intuition and make them more sensitive towards language variation.

Thirdly, as mentioned before DDL is based on the ideas of discovery learning which means that the students acquire knowledge through problem-solving activities using their critical thinking skills as opposed to being explicitly instructed by the teacher.

Finally, DDL represents a bottom-up approach to knowledge acquisition as learner first comes into contact with language input and then arrives at the understanding of vocabulary patterns and grammar rules.

\subsubsection{Concordance-based learning and L3 acquisition}

L3 acquisition is a relatively new field of language research. As it happens with most emerging disciplines, L3 acquisition until recently was not considered a separate area of study but was rather embraced by second language acquisition phenomenon. Although there is still no consensus as to what constitutes L3, following the work of García-Mayo (2012, p. 130) in this research I define L3 as 'a non-native language acquired by learners who have previously acquired or are acquiring two other languages'. Most research studies on L3 acquisition are aimed at investigating the cross-linguistic influence of L1 and L2 on L3 (Cenoz, 2001; Foote, 2009; Mayo, 2012) and other issues of multilingualism. Literature review showed that there have been no studies so far aimed at researching the efficiency of data-driven approach on L3 acquisition.

Research studies on concordance-based learning and language learning can be generally divided into three categories: evaluation of the attitudes (what do 
participants think about DDL?), practices (what classroom activities can be conducted with DDL?) and efficiency (can learners gain benefit from DDL?) (Gilquin \& Granger, 2010).

Empirical studies with experimental research design that fall within the third category and the framework of my research - efficiency - are rather limited in number. In the long-term study of T. Cobb (1997) an experiment was carried out with Arabic-speaking students learning English in which vocabulary of approximately 240 words was taught to the students either through concordances or through other sources of lexical information. 'In a series of tests involving transfer of word knowledge to novel contexts, a small but consistent gain was found for words introduced through concordances' (p. 301). Another study investigated the effectiveness of corpus-based activities for learning verb-adverb collocations compared to traditional activities usually found in course-books (Daskalovska, 2015). The participants of the study, English learners whose native language was Macedonian, showed better results in all parts of the test when learning the collocations with the help of the online concordance. The experimental group demonstrated a gain of $28.24 \%$ on the post-test, while the control group had a gain of $7.72 \%$.

As for vocabulary retention, a study investigating the effect of enriching the vocabulary instruction with the printouts of concordance lines on ability to recall vocabulary was conducted with Iranian EFL students (Jalilifar, Mehrabi, \& Mousavinia, 2014). In this research, the experimental group that dealt with concordance also outperformed the control group in the delayed vocabulary recall test.

The theoretical significance of the present research study is its emphasis on L3 rather than L2 acquisition, the employment of a vocabulary scale representing different levels of vocabulary recognition and, respectively, a detailed view on which aspect of vocabulary - semantic meaning, written form, grammatical function, collocations or the knowledge of semantic relationships vocabulary units build with other units - is learnt and recalled more successfully with concordance-based learning.

\section{Methodology}

\subsection{Research questions}

This study aims to investigate the effectiveness of concordance-based learning on vocabulary learning and retention in L3 (German) acquisition as opposed to traditional explicit vocabulary instruction.

The research questions addressed in the study are as following:

1. Is concordance-based learning more effective in immediate short-term perspective than traditional activities when teaching L3 vocabulary?

2. Is concordance-based learning more effective than traditional activities when recalling L3 vocabulary? 
3. Which aspect of the quality of vocabulary knowledge is learnt more successfully with concordance as opposed to traditional teaching?

4. Are concordance-based activities effective with A1 language level students?

\subsection{Participants}

The participants of the research were 48 students in the third year of their undergraduate study in English language teaching department of Sakarya University, Turkey. They were A1 language learners and had been learning German for 2,5 months as part of their second foreign language university course before the initiation of the study. The participants' native language was Turkish and they also had an advance command of the English language as they had received about 9 years of language instruction on secondary school level and 3 years - on university level prior to the study. The experimental and control group consisted of 24 students each respectively, 9 males and 15 females in the experimental group, 7 males and 17 females in the control group. The assignment of the groups to experimental or control conditions was random, the students who had smartphones available to access the online corpus were assigned to the experimental group.

\subsection{Instruments}

Pre-test and post-test as well as delayed vocabulary recall test were identical and were based on a variation of vocabulary scale developed by the author (see Appendix 1). The parts of the scale represent the multi-level nature of vocabulary knowledge described in the introduction. To calculate the results, one point was given for each item in the vocabulary scale if the participants supplied a suitable answer. Since the focus of the exercises was the acquisition of meaning, points were not deducted for the grammar, syntactic or spelling mistakes unless it affected the intelligibility of the overall meaning. The amount and type of mistakes were later analysed for both groups.

\subsection{Procedure}

The experiment took place during the regular periods of the second foreign language class at the ELT department of Sakarya University. The vocabulary units included for the pre-post- and delayed tests were selected from the glossary of the class course textbook Studio d A1 Deutsch als Fremdsprache (Funk \& Kuhn, 2010) and had not been covered in any of the previous classroom sessions. The chosen vocabulary units were basic and belong to A1 German.

Before the pre-test which showed that the students in both groups had identical knowledge of given vocabulary units as these words had not been discussed in any of the previous classroom activities, the class was first introduced to corpora and concordances. The teacher demonstrated the use of German DWDS Core Corpus (https://www.dwds.de/r) and the participants searched for the words of their own 
choice, analysed and generalized the information from the concordance lines. The pretest was immediately followed by the treatment. The participants of the control group worked with worksheets on conventional vocabulary learning in which (1) they were introduced to 10 key word definitions in English and did exercises (2) on matching the key words with their definitions in German, (3) matching these words with their synonyms and antonyms, (4) as well as an exercise on filling in the blanks with the correct key words they have learned. The experimental group was provided with the same list of 10 key words as the control group and was asked to do the following four tasks: (1) generate and analyse concordance lines for the key words, (2) guess the meaning of each key word from the context in the concordance lines, (3) identify the part of speech of the key words, (4) identify vocabulary units that are used with the key words in their immediate context.

The participants in both groups completed all the tasks individually without the interference from the teacher. Each group was given an hour to do the exercises before the immediate post-test, however, the control group finished 20 minutes earlier than the experimental group.

\section{Results and Discussion}

Since the selected vocabulary items were novel to the participants which was confirmed by the pre-test, the main focus of the research was on the immediate and delayed post-tests. The results of these tests show that, overall, the experimental group gained more knowledge of the given lexical items than the control group, although the results were not evenly distributed across the six sections of the tests. The results of the immediate post-test show that experimental group outperformed control group in four sections of the test (English meaning - by 6.9\%, part of speech by $1.5 \%$, sentence making by $32.6 \%$, making collocations by $22.2 \%$ ). Control group outperformed experimental group in two sections of the test - making synonyms by $46 \%$ and making antonyms by $48.5 \%$. Table 1 shows the difference between the experimental and control groups in the percentage of people who provided correct answers in the immediate post-test. The Roman numbers correspond with the sections of the vocabulary scale.

Table 1. Percentage of people who provided correct answers in the immediate post-test

\begin{tabular}{lcccccc} 
& I & II & III & IV & V & VI \\
\hline $\begin{array}{l}\text { Experimental } \\
\text { group }\end{array}$ & 82.3 & 97 & 72.7 & 4 & 1.5 & 42.7 \\
\hline Control group & 75.4 & 95.5 & 40.1 & 50 & 55 & 10
\end{tabular}

The results of the delayed post-test showed a decline for both groups in the score of all six sections of the test, although similar to the immediate post-test the results were not evenly distributed across the test. The last three sections of the test - 
producing synonyms, antonyms and building collocations accounted for the biggest loss in both groups. Such big loss (above 40\%) might be explained by the fact that the participants needed to remember more lexical information per each vocabulary unit such as immediate context and the relationships the word builds with other units for these sections of the vocabulary scale.

Apart from the loss, the experimental group again outperformed the control group even to a bigger extent in the same four sections of the delayed post-test as compared to the immediate post-test (English meaning - by $10.1 \%$, part of speech by $2.8 \%$, sentence making by $36.3 \%$, making collocations by $18.5 \%)$. Control group outperformed experimental group in two sections of the test - making synonyms by $29 \%$ and making antonyms by $31.5 \%$.

Overall, the experimental group retained more vocabulary knowledge in the four sections of the test than the control group as the percentage of loss between immediate and delayed post-tests is smaller than in case of the control group. Table 2 shows the difference between the experimental and control groups in the percentage of people who provided correct answers in the delayed post-test. Table 3 shows the percentage of loss between immediate and delayed post-tests of the experimental and control groups.

Table 2. Percentage of people who provided correct answers in the delayed post-test

\begin{tabular}{lllllll} 
& I & II & III & IV & V & VI \\
\hline $\begin{array}{l}\text { Experimental } \\
\text { group }\end{array}$ & 70.5 & 93 & 66.3 & 1 & 0.5 & 20.5 \\
\hline Control group & 60.4 & 90.2 & 30 & 30 & 32 & 2
\end{tabular}

Table 3. Percentage of loss between immediate and delayed post-tests of the experimental and control groups

\begin{tabular}{lllllll} 
& $\mathrm{I}$ & $\mathrm{II}$ & $\mathrm{III}$ & $\mathrm{IV}$ & $\mathrm{V}$ & $\mathrm{VI}$ \\
\hline $\begin{array}{l}\text { Experimental } \\
\text { group }\end{array}$ & 14.3 & 4.1 & 8.8 & 75 & 66.7 & 52 \\
\hline Control group & 20 & 5.5 & 25.2 & 40 & 41.2 & 80
\end{tabular}

Although, the points were not deducted for the grammar, syntactic or spelling mistakes that did not affect the overall understanding of the meaning, the mistakes made in the III and VI sections of the test (sentence making and collocations building, respectively) were analysed. Table 4 shows the types and number of mistakes that were made by the two groups in the immediate post-test.

Table 4. Types and number of mistakes made by of the experimental and control groups in the immediate post-test

\begin{tabular}{lll} 
Types of mistakes & Control group & Experimental group \\
\hline agreement (pronouns-nouns / articles-nouns) & 4 & 2
\end{tabular}




\begin{tabular}{lll} 
agreement (verb-prepositions) & 4 & 6 \\
\hline verb conjugation and tenses & 9 & 8 \\
\hline negation & 1 & 2 \\
\hline collocations & 2 & 1 \\
\hline word order & 4 & 5 \\
\hline spelling & 9 & 4
\end{tabular}

Taking into account that experimental group produced more output than the control group, it does not seem plausible to conclude whether it is through concordance-based or traditional method of vocabulary learning that the students make fewer mistakes. In the present study the biggest problem the experimental group had concerned verb conjugation and correct tense form of the verbs. Some examples of the mistakes made in regard to this type were 'sie hattest', 'ich schäfte', 'ich komme gestern' and other examples. Since verb conjugation is not a common process in English, it might need more practice and automatic rather than controlled processing of the grammar meaning for the students to produce correct answers. The major problem the control group faced was spelling besides verb conjugation as in the case of the experimental group. In most cases the participants forgot to capitalize the nouns ('bruder', 'buch' etc) or were influenced by the English spelling ('Theatre'). A brief error analysis also gave an insight into the nature of word order mistakes that were made in roughly same amount in both groups: 'gestern ich war in der Schule', 'ich glaube sie ist freundlich' or 'ich keine habe Zeit für meine Studie'. It seems that the participants followed an English sentence pattern in these examples as in their native language the position of the verb is always at the end of the sentence. A preliminary conclusion can be made that a high level of L2 proficiency has an important activation role on beginner levels of L3 acquisition. Thus, it is important for the L3 instructor to be aware of the students' L2 and to draw their attention to grammar, syntax or spelling issues that are different from L2 while employing any methods of vocabulary teaching.

Based on these results, the answers to the research questions of the present study are positive. In relation to the first and second research question, since the experimental group demonstrated better results in most parts of the two tests and the percentage of loss was smaller with the experimental group in the delayed test, it can be concluded that in this study the concordance-based activities were more effective for learning and retaining German A1 vocabulary units than the traditional activities.

In relation to the third research question and the aspect of vocabulary knowledge that is learnt more successfully with concordance-based activities, the results showed that this approach was especially effective in terms of sentence-making and collocation-building as opposed to traditional vocabulary teaching. It can be illustrated through the percentage difference. The experimental group outperformed the control group by $32.6 \%$ in sentence-making and by $22.2 \%$ in collocation-building in the immediate post-test and by $36.3 \%$ and $18.5 \%$ respectively in the delayed post-test. It can be explained by the fact that in concordance-based activities, the learners are 
exposed to real-life authentic input as well as larger context and example sentences which they discover independently. The fact that the participants had to look at the words surrounding the key words to be able to fill in the table, they had to focus on the key words again which gave them an opportunity for repeated exposure and learning more information about them. The control group had one exercise on filling in the blanks with the correct key words, thus, they were exposed only to one example sentence for each given key vocabulary item.

However, the study showed that synonyms and antonyms were learnt more successfully through traditional instruction as, again, there was a significant difference in results ( $46 \%$ and $48.5 \%$ respectively in the immediate post-test and $30 \%$ and $31.5 \%$ respectively in the delayed post-test) in which the control group outperformed the experimental group. This can be explained by the nature of traditional vocabulary learning tasks that is often aimed at translating the lexical items and positioning the word on the synonym-antonym continuum.

The two other sections of the vocabulary test - providing English equivalents of German vocabulary items and identifying the part of speech showed a slight superiority of concordance-based activities (outperformance by $6.9 \%$ and $1.5 \%$ respectively in the immediate post-test and by $10.1 \%$ and $2.8 \%$ in the delayed posttest) although the difference in these sections was not as sharp as in the remaining sections of the two tests.

Finally, in relation to the last research question, the effectiveness of concordancebased activities with A1 language level students, the results of the study are confirmatory. Since the percentage of the participants who explained the items correctly in the experimental group was quite high (above $70 \%$ in the three sections of the immediate post-test and above $60 \%$ in the delayed post-test), it can be concluded that concordance-based instruction can be used with A1 language level students as well. However, one should take into consideration the fact that the nature of the taught vocabulary should correspond with the language level of the students. In the present study the vocabulary units were taken from the glossary of the course-book, thus, the students' capacity to learn these unites was not exceeded.

\section{Limitations and suggestions for further research}

One of the limitations of the study is that it was conducted in one setting, and the number of participants was not large enough to be able to generalize the results of the study to the whole L3 learner audience. Further studies are needed that would be conducted in other settings and that would include more participants.

In future experimental research studies on concordance-based instruction, SPSS programme can be used to calculate reliability and enhance the strength of the results. The experiment can also be supported by qualitative data that would include participants' perceptions on learning L3 vocabulary with concordance as well as rating of their motivation towards this approach. In informal conversations I had with the participants after the experiment, some of them stated that they had problems 
with the comprehension of the authentic sentences in the German corpus and, thus, had to look through more example sentences to arrive at the understanding of the meaning of each key word.

\section{Conclusions}

The study revealed that concordance-based instruction can be an effective tool to learn and retain L3 vocabulary even on the beginner level of L3 acquisition. As research literature suggests (Beresova, 2015; Daskalovska, 2015; Guan, 2013) and the present study supports, this approach has several advantages for language learners among which are learner autonomy as learners take an active role in working through an extensive language material independently from the teacher; exposure to highly authentic language input which makes learners more sensitive towards language variation; discovery learning as using corpus is an inquiry-based activity and opposes explicit instruction by the teacher which also leads the learners to a bottom-up approach to knowledge acquisition. When using a corpus, the learners have to make their own judgment about the meaning of vocabulary items, thus, the present study showed that concordance-based activities are especially effective in developing learners' ability to use vocabulary in the correct immediate context. However, as the study demonstrated, synonyms and antonyms are learned and retained more successfully through traditional mode of teaching (key word and synonym / antonym matching exercises) since the learners have direct access to this language material in conventional exercises.

\section{References}

Beresova, J. (2015). Authentic materials-enhancing language acquisition and cultural awareness. Procedia-Social and Behavioral Sciences, 192, 195-204.

Caines, A., McCarthy, M., \& O'Keeffe, A. (2016). Spoken language corpora and pedagogical applications. The Routledge Handbook of Language Learning and Technology, 348.

Cenoz, J. (2001). The effect of linguistic distance, L2 status and age on cross-linguistic influence in third language acquisition. Cross-linguistic influence in third language acquisition: Psycholinguistic perspectives, 111(45), 8-20.

Cobb, T. (1997). Is there any measurable learning from hands-on concordancing? System, 25(3), 301-315.

Daskalovska, N. (2015). Corpus-based versus traditional learning of collocations. Computer Assisted Language Learning, 28(2), 130-144.

De Bot, K., Jaensch, C., \& Mayo, M. D. P. G. (2015). What is special about L3 processing? Bilingualism, 18(2), 130.

Faerch, C., Haastrup, K. \& Phillipson, R. (1984). Learner language and language learning. Köpenhamn: Gyldendals sprogbibliotek and Clevedon: Multilingual Matters.

Foote, R. (2009). Transfer in L3 acquisition: The role of typology. Third language acquisition and universal grammar, 37, 89.

Funk, H., \& Kuhn, C. U.A. (2010). Studio d A1/A2 Deutsch als Fremdsprache Kurs- und Übungsbuch. Cornlesen Verlag: Indische Auflage. 
Gilquin, G., \& Granger, S. (2010). How can data-driven learning be used in language teaching? In A. O'Keeffe \& M. McCarthy (Eds.), The Routledge handbook of corpus linguistics (pp. 359-369). London: Routledge.

$\mathrm{Gu}, \mathrm{Y}$. (2002). Gender, academic major, and vocabulary learning strategies of Chinese EFL learners. RELC journal, 33(1), 35-54.

Guan, X. (2013). A study on the application of data-driven learning in vocabulary teaching and learning in China's EFL class. Journal of Language Teaching and Research, 4(1), 105-112.

Hulstijn, J. H. (2001). Intentional and incidental second language vocabulary learning: A reappraisal of elaboration, rehearsal and automaticity (pp. 258-286). NA.

Jalilifar, A., Mehrabi, K., \& Mousavinia, S. R. (2014). The effect of concordance enriched instruction on the vocabulary learning and retention of Iranian EFL learners. ProcediaSocial and Behavioural Sciences, 98, 742-746.

Johns, T. (1991). Should you be persuaded: Two samples of data-driven learning materials (pp. 1-13). NJ.

Mayo, M.D.P.G. (2012). Cognitive approaches to L3 acquisition. International Journal of English Studies, 12(1), 129-146.

O'keeffe, A., McCarthy, M., \& Carter, R. (2007). From corpus to classroom: Language use and language teaching. Cambridge: Cambridge University Press.

Schmitt, N., \& Schmitt, D. (2014). A reassessment of frequency and vocabulary size in L2 vocabulary teaching. Language Teaching, 47(04), 484-503.

\section{Appendix A. Vocabulary scale employed in pre-post and delayed post-tests}

\begin{tabular}{lllll} 
Word & $\begin{array}{l}\text { I know the } \\
\text { meaning of } \\
\text { this word in } \\
\text { English }\end{array}$ & $\begin{array}{l}\text { I know the } \\
\text { part of speech } \\
\text { of this word }\end{array}$ & $\begin{array}{l}\text { I can make a } \\
\text { sentence with } \\
\text { this word in } \\
\text { German }\end{array}$ & $\begin{array}{l}\text { I know } \\
\text { synonyms for } \\
\text { this word }\end{array}$ \\
\hline richtig & $\begin{array}{l}\text { I know antonyms } \\
\text { for this word }\end{array}$ & $\begin{array}{l}\text { I know } \\
\text { collocations this } \\
\text { word builds }\end{array}$ \\
\hline billig & \\
\hline arbeitslos & \\
\hline bequem & \\
\hline reden & \\
\hline verlieren & \\
\hline gestern
\end{tabular}

\section{Copyrights}

Copyright for this article is retained by the author(s), with first publication rights granted to the Journal.

This is an open-access article distributed under the terms and conditions of the Creative Commons Attribution license (CC BY-NC-ND) (http://creativecommons.org/licenses/by-nc-nd/4.0/). 